\title{
THE RELATIONSHIP BETWEEN SYNTACTIC AND SEMANTIC: A STUDY OF LINGUISTIC TYPOLOGY
}

\author{
Antonio Constantino Soares ${ }^{1}$ \\ ${ }^{1}$ Universidade Dili and Instituto Sâo Joâo De Brito \\ Dili, Timor Leste
}

Corresponding Author: Antonio Constantino Soares E-mail:antonio.soares.281170@gmail.com

\begin{tabular}{|c|c|}
\hline ARTICLE INFO & ABSTRACT \\
\hline $\begin{array}{l}\text { Received: 2019-03-27 } \\
\text { Accepted: 2019-11-27 } \\
\text { Published: October } 2019 \\
\text { Volume:3 } \\
\text { Issue: } 2 \\
\text { DOI: } \\
\text { https://doi.org/10.33019/lire.v3i2.49 } \\
\text { KEYWORDS }\end{array}$ & $\begin{array}{l}\text { This research entitled "The Relationship between Syntactic and } \\
\text { Semantic : A Study of Linguistic Typology." is intended to give a } \\
\text { clear descriptions related to the relationship between syntactic and } \\
\text { semantic on some languages. This research was focused on some } \\
\text { clause structures typologycally either syntactically or semantically. } \\
\text { The scope of this research was more focused on the transitive verbs } \\
\text { to have more descriptions related to the relationship between } \\
\text { syntactic and semantic to find out whether a clause structure on }\end{array}$ \\
\hline $\begin{array}{l}\text { Syntactic,semantic, linguistics, typolo } \\
\text { gy,agreement }\end{array}$ & $\begin{array}{l}\text { syntactic can be accepted or cannot be accepted semantically. The } \\
\text { theory of linguistics typology was appliedin this research because } \\
\text { the principle of linguistics typpology is to find out the similarities } \\
\text { and the differences among all the type of languages universally. } \\
\text { The introspective reflexive and the descriptive method were } \\
\text { applied to gain the data in this research and the qualitative } \\
\text { descriptive method was applied to analyse the data. }\end{array}$ \\
\hline
\end{tabular}

\section{INTRODUCTION}

Talking about linguistics typology, Moravcsik (2013) divides linguistics into four main types such as Phonology typology, Morphology typology, Syntax typology and semantic typology. Comrie 1988 b also explains that typology linguistics is a study of language classification of domain. Based on the statements above, this research was more focused on the relationship between syntactic and semantic structures. Brown and Miller (1994:64) also state that the category Pred offers a unique environment for the classification of copular verbs. It also enables us to identify which NPs' are predicate, information we need, in English, to ensure that predicate NPs agree in number with the subjects of the sentence, and in other languages to make the correct statement about the agreement of adjectives. Besides, Maclin (1994:35) also says that the subject and main verb of a clause must agree in number. Use a singular verb with a singular noun or pronoun or with an uncountable (mass) noun. Use a plural verb with a plural noun or pronoun. Countable nouns that indicate more than one person or thing are plural in English. The research was more focused on the transitive verbs that would be expanded on Subject-PredicateAgreement, Subject-ObjectAgreement and Predicate-ObjectAgreement. Typologycally, there are some languages that have Subject-PredicateAgreement and they have been discussed by a numbers of linguists, however there are not many linguistics lovers who focus deeply on Subject-Object Disagreement, Predicate-ObjectDisagreement and Subject-Predicate-Object Disagreement because most the researchers just focused their researches to the Subject-PredicateAgreement. In this short article, it would be interesting to analyse them typologycally either on syntactically or semantically. The data used in this 
P-ISSN: 2598-1803

E-ISSN: 2 581-2130

Volume 3 Number 2 October 2019

research were taken from 4 languages differently.Those are English language (EL), Tetun Terik (TT), Makasae language (ML), and bahasa Indonesia (BI). In this paper, the writer would like to compare those languages to find out the similarities and the differences related to the Agreement and Disagreement on some clause structures either syntactically or semantically.

\section{LITERATURE REVIEW}

Typologycally, Tetun Terik (TT) is also an Accusative language with SVO word order and with OSV word order and it belongs to an Austronesian language. (TT) is spoken in some places such as in Atambua, west Timor and Viqueque. Canonically, the word order of TT is the same as Tetun Dili (TD), however (TD) does not have any case marking like (TT). The data on the sentences (16), (17), (18). (19) and (20) show that there are SUB and PRED agreement among the data above.The data on (16) consists of three main constituents syntactically. $H a^{\prime} u(I)$ is a pronoun and it functions as the SUB, $k a$ (eat) is a verb (V) and it functions as the PRED, hetu (rice) is a noun $(\mathrm{N})$ and it functions as the OBJ. Based on the Grammatical category, $h a^{\prime} u(I)$ is a first singular pronoun, therefore it must agree with the PRED $k a$ (eat). The data on the sentence(17) also shows that $o(y o u)$ is a second person singular pronoun and it functions as the SUB, ma (eat) is a verb (V) and it functions as the PRED, paun (bread) is a noun (N) and it functions as the OBJ.From the data, it can be seen that the SUB pronoun o(you) must agree with the PRED ma. The sentence on the data (18) shows that nia (s/he belongs to the third singular pronoun and it functions as the SUB, na (eat) is a verb (V) and it functions as the PRED, dosi (cake) is a noun and it functions as the OBJ. From the data, it can be seen that the SUB pronoun nia (s/he must agree with the PRED na (eat). The data on the sentence (19) shows that ita (we) belongs to the first person plural and it functions as the SUB, ha (eat) is a verb (V) and it functions as the PRED, modo (vegetables) is a noun $(\mathrm{N})$ and it functions as the object. From the data, it can be seen that the SUB pronoun ita (we) must agree with the PRED ha (eat). The data on the sentence (20) shows that sira (they) belongs to a noun (N) and it functions as the SUB, ra (eat) is verb $(V)$ and it functions as the PRED, paun (bread) is a noun $(\mathrm{N})$ and it functions as the OBJ. In this case the SUB sira (they) must agree with the PRED ra (eat).

\section{METHODOLOGY}

The theory of linguistics universal was proposed in this research. The data used in this research were taken from four different languages. The reflexif method and descriptive method were applied in this research. The technique used in this research were elicitation and note taking. All the data were collected based on their classifications then analysed them by using descriptive method. The data used in this research were gained from the writer himself because the writer is able to speak some languages well. A speaker of certain languages may use himself or herself as the key informan to provide the data in a research because they are capable of correcting the data by themselves whether the data gained can be accepted grammatically or ungrammatically (Artawa, 1998). 
Volume 3 Number 2 October 2019

\section{RESULTS AND DISCUSSION}

A. The Subject-Predicate Agreement of Transitive Verbs in English Language (EL)
1. Cows eat every day.
$P N$ eat NP
'Cows eat every day'
2. A cow eats every day.
$N P$ eat NP
'A cow eats every day'
3. The cow eats every day.
$N P$ eat NP
'The cow eats every day'

Typologycally, English is known as an acussative language with SVO word order canonically, with OSV alternation. The sentence on the example (1) consists of three constituents syntactically. Based on the grammatical category, cows is a (NP), eat is a (V) and every day is a (NP). Syntactically, cows function as the SUB, eat functions as the PRED, and every day functions as the Time Modifier. The data on the sentence above can be seen that cows are in the plural form and they are consindered as the general animal therefore the definite article is not used as the modifier. There is not any morphem added on the predicate eat because the subject cows categorized in plural (NP). The data on (2) also consists of three constituents syntactically. Based on the grammatical category, The cow (NP)functions asthe SUB, eats (VP)functions as thePREDand every day is a noun phrase (NP) and it functions as the time modifier. The sentence on (3) consists of three constituents syntactically. The cow is a noun phrase (NP) and it functions as the subject, eats is a verb and it functions as the PRED, every day is a noun phrase (NP) and it functions as the time modifier. The bound morpheme " $S$ "must be added to thePRED eat- $S$ because the cow is the third singular SUB, therefore it is called as the SUB and PRED agreement.

B. The Subject-Predicate Disagreement of Transitive Verbs in English Language (EL)

$$
\begin{aligned}
& \text { 4. *Horses write. } \\
& \text { NP write } \\
& \text { *'Horses write' } \\
& \text { 5. *A horse cooks, } \\
& \text { NP cook } \\
& \text { *A horse cooks' }
\end{aligned}
$$

The data on the sentence (4) above consists of two main constituents syntactically. The horses (NP) functions as the SUB and writes (VP)functionsasthe PRED. From the data, they can be concluded that the subject can agree with the PRED syntactically, however the 
SUB does not agree with the verb semantically. The data on the sentence (5) also consists of two main constituents. Based on the grammatical category, the horse is a noun phrase (NP) and it functions as the SUB syntactically and the verb phrase cooks (VP)functions as the PRED. Of the data, it can be concluded that based on the syntactic function, the subject agrees with the PRED, however they cannot be accepted semantically because a horse (NP)cannot do the cooking activity because it is a non-human.

C. The Subject-Object Disagreement of Transitive Verbs in English Language (EL)
6. *Tigers eat grass.
NP eat grass
* 'Tigers eat grass'
7. *The cow eats meat in the field. NP eat meat $p p$
*'The cow eats meat in the field'

The data on the sentence (6) consists of three constituents. Based on the grammatical categories, tigers (NP)functions as the SUB, eat (VP) functions as the PRED and grass functions as the OBJ syntactically. Grammatically, the SUB and the PRED agree one to another, however the SUB does not agree with the OBJ semantically. The data on the sentence (7) consist of three main constituents. The cows (NP) functions as the SUB, eats (VP)functions as the PRED and in the field (PP)functions as the place modifier syntactically. Grammatically, the sentences on the data (6) (7) are correct, however each SUB does not agree with the OBJ semantically.

D. The Predicate-Object Disagreement of Transitive Verbs in English Language (EL)
8. *Cows eat water.
NPeat water
* 'Cows eat water'
9. *A goat drinks bread. NP drink bread
*'A goat drinks bread'

The data on the sentence (8) also consists of three constituents syntactically. Cows (NP)phrasal category and it functions as the SUB, eats (VP)functions as the PREDand water $(\mathrm{N})$ functions as the OBJ. The data on the sentence (9) also consists of three constituents syntactically. A goat (NP) functions as the SUB, drinks (VP)functions as the PRED and bread noun (N) functions as the OBJ. From the data above, it can be seen that the SUB agrees with the PRED, however the PRED does not agree with the OBJ semantically.

E. The Subject-Predicate Disagreement of Transitive Verbs in Makasae language (ML)

\section{0. *Kuda laa kereke.}


*'Horses write'

11. *Bibi u tina. PN ART cook

*'A goat cooks'

Typologycally, Makasae language (ML) belongs to Trans new Guinea and also known as an Accusative language with SOV word order or with an alternation as OSV. The data on (10) also consists of two main constituents. Based on the grammatically category, kuda (horse) (laa plural marking)is a noun phrase (NP) and functions as the SUB. Laa functions asthe modifier and behaves as the plural marking because Makasae language (ML) is known as postmodifier and not premodifier. Kereke (write) is a verb and it functions as the PRED. From the data, it can be seen that the SUB can agree with the PRED based on the sentence element, however the SUB does not agree with the verb semantically because kuda (horse) is a non-human. The data on the sentence (11) also consists of two main constituents syntactically. Based on the grammatical category Bibi $u$ (a goat) is a noun (NP)andit functions as the SUB, tina (cook) is a verb (V)and it functions as the PRED. From the data, it can be seen that the noun phrase (NP) bibi u (a goat) does not agree with the Verb (V) tina (cook) because the SUB is a non-human. The data can be concluded that all noun phrases (NP) can be the SUB syntactically, however there must be any predicate that can agree with the certain noun phrase (NP) that posts the SUB position.

F. The Subject-Object Disagreement of Transitive Verbs in Makasae language (ML)

\section{2. *Liaun laa rou nawa. PN P.MRK grass eat \\ * 'Lions eat grass' \\ 13. *Bibi u seu nawa. PN ART meat eat *'Goat eats meat'}

The sentence on (12) grammatically consists of three constituents. Liaun laa (the lions) belong to a noun phrase(NP)and theyfunctions as the SUB. Laa (plural marking) functions as the modifier, rou (grass) is noun (N)and it functions as the OBJ and nawa (eat) is a verb (V) and it functions as the PRED. Syntactically.The SUB liaun (lions) disagree with the OBJ rou (grass) because as we know that liaun(lions)are categotized as carnivora animals and not as herbivora animals therefore the SUB disagrees with the OBJ Semantically. The data on the sentence (13) also consists of three constituents. Grammatically, Bibi $u$ (a goat) is a noun phrase (NP) and it functions as the SUB, $u$ (as an indefinite article) and it functions as the modifier, seu (meat) is a noun (N) and it functions as the object, nawa(eat) is a verb and it functions as the PRED. Makasae language is known as a postmodifier and not a premodifier, therefore all kinds of modifiers must be put after the head of the noun. The data on (13) also shows that the SUB disagrees with the OBJ semantically because bibi(goat) is a herbivora and not as a carnivora. 
LIRE JOURNAL (JOURNAL OF LINGUISTICS AND LITERATURE)

P-ISSN: $\underline{2598-1803}$

E-ISSN: 2581-2130

Volume 3 Number 2 October 2019

G. The Predicate-Object Disagreement of Transitive Verbs in Makasae language (ML)

14. *Bibi u paun gehe.

PN ART bread drink

'A goat drinks bread'

15. \% Arabaw laa ira nawa.

PN P.MRK water eat

'Cows eat water'

The data on the sentence (14) consists of three main constituents syntactically. Bibi $u$ (a goat) is a noun phrase (NP) and it functions as the SUB, $u$ (is a definite article) and it functions as thepostmodifier of a noun, paun (bread) is a noun (N) and it functions as the OBJ, gehe(drink) is a verb (V) and it functions as the OBJ. From the data, it can be concluded that the PRED disagrees with the OBJ semantically because the PRED gehe (drink) must agree with the liquid things. The data on the sentence (15) constituently also consists of three main constituents. Arabaw laa is a noun phrase (NP) and it functions as the SUB, laa(plural postmodifier), ira (N) and it functions as the OBJ, nawa (eat) is a verb $(\mathrm{V})$ and it functions as the main PRED. From the data, it can be seen that the PRED nawa (eat) refers to drink grammatically can be accepted in Makasae language (ML) especially for Quelicai dialect only, however nawa cannot be applied instead of drink in other dialects speakers of (ML) such as Ossu, Laga, Loroo and watulari.

H. The Subject-Predicate-Object Agreement of Transitive Verbs in Tetun Terik language (TT)

16. \% Ha'u ka hetu.

1ST.SGL.PRO eat rice

'I eat rice'

17. \% O ma paun.

2ND.SGL.PRO eat bread

'you eat bread'

18. \% Nia na dosi.

3RD.SGL.PRO eat cake

'S/he eats rice'

19. \% Ita ha modo.

IST.PLR.PRO eat vegetables

'we eat vegetables'

20. \% Sira ra paun.

3RD.PLR.PRO eat bread

'They eat bread'

Typologycally, Tetun Terik (TT) is also an Accusative language with SVO word order and with OSV word order and it belongs to an Austronesian language. (TT) is spoken in 
Volume 3 Number 2 October 2019

some places such as in Atambua, west Timor and Viqueque. Canonically, the word order of TT is the same as Tetun Dili (TD), however (TD) does not have any case marking like (TT). The data on the sentences (16), (17), (18). (19) and (20) show that there are SUB and PRED agreement among the data above.The data on (16) consists of three main constituents syntactically. $H a$ ' $u$ (I) is a pronoun and it functions as the SUB, $k a$ (eat) is a verb (V) and it functions as the PRED, hetu (rice) is a noun $(\mathrm{N})$ and it functions as the OBJ. Based on the Grammatical category, $h a^{\prime} u(I)$ is a first singular pronoun, therefore it must agree with the PRED ka (eat).The data on the sentence(17) also shows that $o(y o u)$ is a second person singular pronoun and it functions as the SUB, ma (eat) is a verb (V) and it functions as the PRED, paun(bread) is a noun (N) and it functions as the OBJ.From the data, it can be seen that the SUB pronoun o(you) must agree with the PRED ma. The sentence on the data (18) shows that nia ( $s$ /he belongs to the third singular pronoun and it functions as the SUB, na (eat) is a verb (V) and it functions as the PRED, dosi (cake) is a noun and it functions as the OBJ. From the data, it can be seen that the SUB pronoun nia (s/he must agree with the PRED na (eat).The data on the sentence (19) shows that ita (we) belongs to the first person plural and it functions as the SUB, ha (eat) is a verb (V) and it functions as the PRED, modo (vegetables) is a noun $(\mathrm{N})$ and it functions as the object. From the data, it can be seen that the SUB pronoun ita (we) must agree with the PRED ha (eat). The data on the sentence (20) shows that sira (they) belongs to a noun (N) and it functions as the SUB, ra (eat) is verb $(V)$ and it functions as the PRED, paun (bread) is a noun $(\mathrm{N})$ and it functions as the OBJ. In this case the SUB sira (they) must agree with the PRED ra (eat).

I. The Subject-Predicate Disagreement of Transitive Verbs in Tetun Terik Language (TTL)

\section{1. *Kuda sira hakerek. PN P.MRK write \\ *'Horses write' \\ 22. *Karau ida tuku. PN ART hit 'A cow punches/hits'}

The data on the sentence (21) shows that kuda sira(horses) is a noun phrase (NP) and it functions as the SUB, sira is a plural marking and it functions as the modifierbecause (TT) is also known as a post-modifier. Hakerek (write) is a Verb (V) and it functions as the PRED. The data above shows that the SUB disagrees with the PRED because the SUB is a non-human that can not do any certain action verbs that can be done by the humans. The data on the sentence above is acceptable syntactically, however it is unacceptable semantically. The data on the sentence (22) also showed that karau ida (a cow) is a noun phrase (NP) and it functions as the SUB, tuku (punches) is a verb (V) and it functions as the PRED. The data shows that the SUB disagrees with the PRED either because karau(cow) is a non-human and it cannot do any certain action verbs as humans.

\section{J. The Subject-Object Disagreement of Transitive Verbs in Tetun Terik Language (TTL)}


23. *Liaun sira ra du'ut. PN P.MRK eat grass

* 'Lions eat grass'

\section{4. *Busa ida na duut. PN ART eat grass \\ *'A lion eats grass'}

The data on the sentence (23) consists of a noun phrase (NP), a verb (V) and a noun (N). Liaun (lion) the noun phrase (NP functions as the SUB, sira (plural marking as the modifier) ra (eat) functions as the PRED, the noun $(\mathrm{N})$ duut (grass) functions as the object. The data on the sentence (24) also consists of a noun phrase (NP), a verb (V) and a noun (N). The noun phrase (NP) busa ida (a cat) functions as the SUB, ida (ART) functions as the indefinite article, $n a(\mathrm{~V})$ functions as the PRED. Of the data above, they can be seen that the SUB disagree with the OBJ semantically because liaun and (busa) are carnivora and not herbivora.

K. The Predicate-Object Disagreement of Transitive Verbs in Tetun Terik Language (TTL)

\section{5. *Karau ra bee. $P N$ eat water \\ *'Horses eat water' \\ 26. *Bibi ida na bee. PN ART eat water \\ *'A goat eats water'}

The data on the sentence (25) showed that karau (cow) is a noun $(\mathrm{N})$, ra(eat) as verb $(\mathrm{V})$, bee (water) is a noun (N). Syntactically, karau functions as the SUB, ra functions as the PRED, bee functions as the OBJ. The data on the sentence (26) also showed that bibi $i d a($ a goat) is a noun phrase (NP), ida(one), na(eat) is a verb (V), bee (water) is a noun (N). Grammatically, bibi ida functions as the OBJ, $n a$ fumctions as the PRED, bee functions as the OBJ as well. From the data, it can be seen that the SUB disagrees with the PRED ra and $n a$ because the PRED $r a$ and $n a$ must be followed by a non-liquid things in TT.

L. The Subject-Predicate-Object Agreement of Transitive Verbs in Bahasa Indonesia (BI)

27. Seekor sapi makan rumput.

ART cow eat grass

'A cow eats grass'

28. Domba itu makan daun.

PN DEM eat leaves

'That sheep eats' 
The data on the sentences above were taken from bahasa Indonesia (BI). Typologycally, (B.I) is known as an Accusative language and it belongs to the Austronesian language with SVO word order or with OSV alternation word order. The data on the sentence (21) consists of three main constituents as one unit syntactically. $S E$ ekor morphologically, $S E$ - a bound morpheme (one/a) is an article, sapi(cow) is a noun $(\mathrm{N})$, makan (eat) is a verb (V), rumput (grass) is a noun (N). (BI) is known as a premodifier or postmodifier. The article SE-ekor must be in initial position as the modifier, however demonstrative adjectives must be in the final position after a noun $(\mathrm{N})$ or a noun phrase (NP). Grammatically, sapi functions as the SUB, makan functions as the PRED, grass functions as the OBJ. The data on the sentence (28) also shows that domba is a noun $(\mathrm{N})$, itu (DEM), makan is a verb (V), daun is a (noun). Syntactically, domba functions as the SUB, itu functions as the determiner(D), makan functions as the PRED, and daun functions as the OBJ.

M. The Subject-Predicate Disagreement of Transitive Verbs in Bahasa Indonesia (BI)

$$
\begin{aligned}
& \text { 29. *Semua sapi memasak. } \\
& \text { D cow cook } \\
& \text { 'All cows cook' } \\
& \text { 30. *Se-ekor sapi menulis. } \\
& \text { ART cow write } \\
& \text { 'A cow writes' }
\end{aligned}
$$

The data on the sentences (29) consists of two main constitiuents syntactically. semua (all) is a quantifier, sapi is a noun phrase (N), and memasak is a verb (V). Grammatically, semua functions as the modifier, sapi functions as the SUB, and memasak functions as the PRED. The data on the sentence (30) also consists of two constituents syntactically. SEekor is (an article), sapi is a noun (N), menulis is a verb (V). SE-ekor functions as the modifier, sapi functions as the SUB, menulis functions as the PRED. From the analysis, it can be seen that the SUB on the data (29) and (30) disagree with the PRED because semua sapi and SE-ekor sapi are non-humans.

N. The Subject-Object Disagreement of Transitive Verbs in Bahasa Indonesia language (BI)

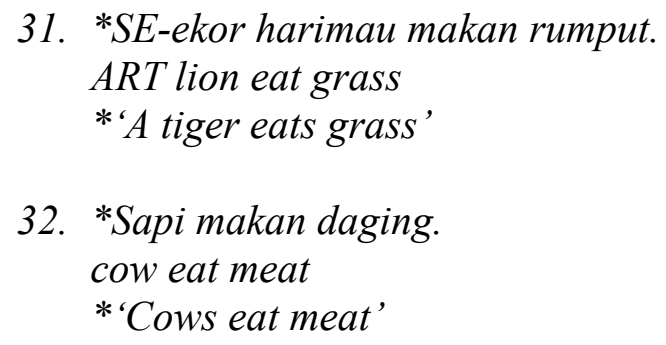

Each data on the sentences (31) and (32) consist of three constituents grammatically. SE-ekor harimau(a tiger) on the data (31) is a noun phrase (NP), SE-ekor (a/one), 
P-ISSN: 2598-1803

E-ISSN: 2581-2130

Volume 3 Number 2 October 2019

makan(eat), rumput (grass) is a noun (N). Syntactically, SE-ekor functions as the modifier, harimau functions as the SUB, makan functions as the PRED, and rumputfunctions as the OBJ. From the analysis, it can be seen that the SUB disagrees with the OBJ because harimau is categorized as the carnivora and not as a herbivora. The data on the sentence (31) shows that sapi (cow) is a noun $(\mathrm{N})$, makan (eat) is a verb, daging is a noun $(\mathrm{N})$. Based on the grammatical function, sapi functions as the SUB, makan functions as the PRED and daging functions as the OBJ. From the data, it can be seen that the SUB disagrees with the OBJ because sapi is categorized as a herbivora and not a carnivora.

O. The Predicate-Object Disagreement of Transitive Verbs in Bahasa Indonesia (BI)

\author{
33. *SE-ekor sapi makan air. \\ ART cow eat water \\ 'A cow eats water' \\ 34. *Kita minum nasi . \\ SND.P.PRO eat nasi \\ 'We drink rice'
}

The data on the sentence (33) above consists of three main constituents. Grammatically, SE-ekor sapi (a cow) is (NP), se- (a lone), makan (eat) is a verb (V), air (water). Syntactically, SE-ekor functions as the modifier, sapi functions as the SUB, makan functions as the PRED, water functions as the object. Data on the (34) also consists of three main constituents. Grammatically, kita (we) is a (pronoun), drink is a verb (V), and nasi (rice) is a noun (N). Syntactically, kita functions as the SUB, drink functions as the PRED, and nasi functions as the OBJ. From the analysis, it can be seen that the PRED makan disagrees with the OBJ water in (BI) semantically because the PRED makan must be followed by a non-liquid item. Then, the data on the sentence (35) also shows that the PRED minum disagrees with the OBJ rice semantically because the PRED minum must be followed by a liquid thing and not a non-liquid thing.

\title{
5. CONCLUSION
}

Based on four languages used as the data in this research such as English language (EL), Makasae language (ML), Tetun Terik (TT), and bahasa Indonesia (BI) show that each of those languages has their own similarities and differences either from their word orders syntactically or semantically. Based on the word order, (EL) is canonically known as SVO with OSV alternation, the word order of (ML) is canonically known as SOV with OSV alternation. The word order of (TT) is canonically known as SVO with OSV alternation. The word order of (BI) is canonically known as SVO with two possible alternation typologycally whether OSV or VOS. The analysis shows that if a noun $(\mathrm{N})$ or a noun phrase (NP) are husbandries such as cow, horse, pig, dog, goat, and sheep etc, they will not agree with some action verbs such as cook, write, tuku, boil, type and read etc.This disagreement is effective for all types of languages over the world. Some nouns (N) like grass and leaves that function as the OBJ also disagree with the SUB of a clause if the SUB is a group of carnivora animals such as lion, leopard, tiger and cat etc. This disagreement is also effective for all types of languages around the world. The PRED nawa (eat) in Makasae Language (ML) can agree with any kinds ofnouns $(\mathrm{N})$ or noun phrases 
LIRE JOURNAL (JOURNAL OF LINGUISTICS AND LITERATURE)

P-ISSN: 2598-1803

E-ISSN: 2581-2130

Volume 3 Number 2 October 2019

(NP) that post the SUB position. After all the data were analysed syntactically, the result showed that there are some verbs that disagree with the certain SUB, some Verbs disagree with the OBJ, some Verbs disagree with both SUB and OBJ semantically. The result of the analysis can also be seen that most languages with SUB-PRED-OBJ-Agreement are considered as the most dominant in both syntactic and semantic structures.

\section{ABOUT THE AUTHOR(S)}

The author is Master Degree Graduate from University of Udayana, Bali. And now, he is the lecturer in Universidade Dili and Instituto Sâo Joâo De BritoDili, Timor Leste

\section{References}

Brown \& Miller. (1994). Syntax: A Linguistic Introduction to Sentence Structure. Second edition. London.

Comrie, B. (1983). Language Universal and Linguistics Typology. Oxford: Basil Blackwell. Limited.

Dixon, R.M.W. (2010). Basic Linguistics Theory.Volume 2. The Cairns Institute. James Cok Uiniversity Press.

Maclin, A. (1994). Reference Guide to English: A Handbook of English as a Second Language. Published by the Materials Branch, English Language Program Division United States Information Agency Washinton D.C. 20547.

Moravcsik, A. (2013). Introducing language Typology. Cambridge: Cambridge. University Press.

Mallinson, B. (1981). Language Typology: Cross-Linguistic Studies in SyntaxAmsterdam: North Holland Publishing Company. 